\title{
A target-controlled infusion system with bispectral index monitoring of propofol sedation during endo- scopic submucosal dissection
}

Authors

Institution
Atsushi Imagawa, Hidenori Hata, Morihito Nakatsu, Akihiro Matsumi, Eijiro Ueta, Kozue Suto, Hiroyuki Terasawa, Hiroyuki Sakae, Keiko Takeuchi, Manabu Fujihara, Hitomi Endo, Hisae Yasuhara, Shinichi Ishihara, Hiromitsu Kanzaki, Hideki Jinno, Hidenori Kamada, Eisuke Kaji, Akio Moriya, Masaharu Ando

Department of Gastroenterology, Mitoyo General Hospital, Kagawa, Japan submitted

20. February 2014 accepted after revision 11. June 2014

\section{Bibliography}

DOI http://dx.doi.org/

10.1055/s-0034-1377519

Published online: 17.11.2014

Endoscopy International Open 2015; 03: E2-E6

(c) Georg Thieme Verlag KC Stuttgart · New York

E-ISSN 2196-9736

\section{Corresponding author}

Atsushi Imagawa, MD PhD

Department of

Gastroenterology

Mitoyo General Hospital

708 Himehama

Toyohama

Kan-onji

Kagawa

Japan 769-1695

Fax: +81-875-524936

imagawa-gi@nifty.com
License terms

() (1) $\ominus \circledast$
Background and study aims: Propofol administration via a target-controlled infusion system with bispectral index monitoring (BIS/TCI system) is expected to prevent complications from sedation during complex and long endoscopic procedures. We evaluated the feasibility of setting the BIS/TCI system for non-anesthesiologist administration of propofol (NAAP) during endoscopic submucosal dissection (ESD).

Patients and methods: From May 2009 to February 2013, 250 patients with esophagogastric neoplasms were treated with ESD using the BIS/TCI system with NAAP. In the TCI system, the initial target blood concentration of propofol was set at $1.2 \mu \mathrm{g} / \mathrm{mL}$. The titration speed of propofol was adjusted according to the BIS score and the movement of the patient. The BIS target level ranged from moderate to deep sedation, at which a stable BIS score between 60 and 80 was obtained.

\section{Introduction}

Propofol is an ideal agent for endoscopic treatment because it is associated with a rapid onset of action with a short duration of effect [1 - 4]. Recently, non-anesthesiologist administration of propofol (NAAP) has been reported and it was carried out safely during endoscopic treatment as well as endoscopic screening procedures [5-13]. In addition, it is important to maintain a stable condition in the patient, especially during complex and long endoscopic procedures such as gastric and esophageal endoscopic submucosal dissection (ESD). However, oxygen desaturation $\left(\mathrm{SpO}_{2}<90\right)$ and hypotension $(\mathrm{BP}<90 \mathrm{mmHg})$ are drawbacks of propofol sedation. Regarding oxygen desaturation, we reported that the frequencies of $\mathrm{SpO}_{2}<90$ were $9.0-10.2 \%$ when propofol sedation was used during ESD [14]. Recently, very high rates of desaturation using propofol sedation have been reported; the rates of desaturation $\left(\mathrm{SpO}_{2}<90\right)$ were $12.5-44.5 \%$, and surprisingly,
Results: In $80.4 \%$ of patients, it was possible to maintain stable sedation with a blood concentration of propofol of less than $1.6 \mu \mathrm{g} / \mathrm{mL}$ using $\mathrm{TCl}$ throughout the ESD procedure. The default setting for ideal blood concentration of propofol was $1.2 \mu \mathrm{g} / \mathrm{mL}$, because the medians of the lower and upper bounds of blood concentration were $1.2 \mu \mathrm{g} / \mathrm{mL}$ (range $0.6-1.8 \mu \mathrm{g} / \mathrm{mL}$ ) and $1.4 \mu \mathrm{g} / \mathrm{mL}$ (range $1.0-3.8 \mu \mathrm{g} / \mathrm{mL}$ ), respectively. Although hypotension occurred in 27 patients $(10.8 \%)$, oxygen desaturation occurred in only nine patients (3.6\%), and severe desaturation in only two patients $(0.8 \%)$.

Conclusions: Using our settings, it is possible for a non-anesthesiologist to maintain stable sedation during a lengthy endoscopic procedure through propofol sedation with a BIS/TCI system.

the rates of severe desaturation $\left(\mathrm{SpO}_{2}<85\right)$ were $3.7-30.9 \%$ in screening esophagogastroduodenoscopy, colonoscopy, and endoscopic retrograde cholangiopancreatography (ERCP), and moderate sedation should be required [15-18]. Gotoda et al. [19] reported that the ESD procedure was carried out with NAAP and with manually controlled infusion. In that study, propofol was carefully and slowly administered, but desaturation occurred in $6.6 \%$ of the procedures [19].

In order to avoid these adverse events, studies on the efficacy and utility of bispectral index (BIS) monitoring of propofol sedation during endoscopic procedures have been conducted. The score of BIS was calculated from the patient's electroencephalograph and this score varies between 0 (coma) and 100 (awake), and correlates with the degree of sedation. The target level of BIS is from moderate to deep sedation until obtaining a stable BIS score of between 60 and 80.There were several reports on the effectiveness of BIS monitoring of propofol sedation in reducing the 
recovery time during ERCP and in the satisfaction of patients and the operator during ESD. On the other hand, because the use of a BIS monitor is not able to reduce the dose of propofol, its usefulness has been controversial $[14,20]$.

A target-controlled infusion (TCI) system that is built on the pharmacokinetics of propofol, along with a computer-assisted infusion algorithm can be suitable. A steady plasma concentration of propofol can be achieved by adjusting titration automatically [21].

In the field of dental anesthesia for patients with intellectual disability, it was reported that propofol sedation using BIS-guided TCI is a useful and safe method in the management of patients [22]. Propofol administration via a TCI system with a BIS monitor (BIS/TCI system) is expected to prevent complications of sedation and this system will also reduce the risk of over-dosage. Also, this system will be introduced for sedation administered by a non-anesthesiologist during endoscopic treatment. The aim of this study was to evaluate the feasibility of setting the BIS/TCI system for sedation by NAAP during ESD.

\section{Patients and methods}

The study was approved by the Ethics Committee of Mitoyo General Hospital, Kagawa, Japan. From May 2009 to February 2013, 250 patients with esophagogastric neoplasms were treated with ESD using the BIS/TCI system of propofol sedation. Adult patients with American Society of Anesthesiologists (ASA) classification $1-3$, who were diagnosed with gastric cancer or esophageal cancer and who provided written informed consent, were included in this study. Patients who were assigned to ASA classification $4-5$, and patients with egg or soy allergy, were excluded. All patients underwent chest radiography, electrocardiography, blood analysis including liver and renal function tests, and spirometry before treatment.

\section{ESD procedure}

A mark was made around the lesion using a Dual Knife (KD-650 L/ Q; Olympus, Tokyo, Japan) in soft coagulation mode. Then Glyceol (10\% glycerol and 5\% fructose in normal saline (NS) solution; Chugai Pharmaceutical Co., Tokyo, Japan) with small amounts of epinephrine and indigo carmine or Muco Up $(0.4 \%$ sodium hyaluronate; Johnson \& Johnson K.K., Tokyo, Japan) diluted two times with glycerol solution was injected into the submucosal layer. Incision and dissection were carried out primarily using the Dual Knife, and also the Olympus ITknife nano (KD-612L; Olympus) and mucosectome2 (DP-D2518; HOYA Pentax, Tokyo, Japan) [23-26].

\section{Propofol administration with BIS/TCI system}

In the team for endoscopic treatment, there were at least four persons including the operating doctor with at least three assistants (one doctor and two nurses). Propofol was administered by nonanesthesiologists, including endoscopists and nurses who had attended the Immediate Cardiac Life Support course. This is one of the training courses specifically provided in Japan, and includes Basic Life Support and a part of the Advanced Cardiovascular Life Support [27]. They were also trained in administering propofol sedation under the supervision of anesthesiologists. Supplemental oxygen $(2 \mathrm{~L} / \mathrm{min}$ via a nasal cannula) and pentazocine $(15 \mathrm{mg}$, via the intramuscular route; Daiich-Sankyo Co., Tokyo, Japan) were administered at the beginning of the procedure. The propo- fol used in this study was Diprivan (AstraZeneca, Osaka, Japan). In the TCI system, the initial target blood concentration of propofol (effect-site concentration: $\mathrm{Ce}$ ) was set at $1.2 \mu \mathrm{g} / \mathrm{mL}$. The initial Ce was chosen for moderate sedation on the basis of a previous study and our pilot experiments on Japanese patients [22].

The titration speed of propofol was adjusted by increasing or decreasing the blood concentration of propofol by $0.2 \mu \mathrm{g} / \mathrm{mL}$ according to the BIS score and the movement of the patient. If the patient began to move or the BIS score was over 85 , the blood concentration of propofol was increased by $0.2 \mu \mathrm{g} / \mathrm{mL}$. Movement of the patient was considered to have occurred if there were movements of the upper and lower extremities of the patient two or more times in succession during the procedure. In contrast, if the BIS score was less than 50 or the vital signs showed abnormalities, the blood concentration of propofol was decreased by $0.2 \mu \mathrm{g} / \mathrm{mL}$. Abnormality of vital signs was defined as just one occurrence among $\mathrm{SpO}_{2}<90 \%, \mathrm{BP}<90 \mathrm{mmHg}$ and bradycardia $(\mathrm{PR}<50 \mathrm{bpm})$ during the procedure. Stable sedation was defined as the condition in which the patient had no movement and no abnormalities of vital signs. Under stable sedation, it was possible to carry out the treatment while having a good endoscopic view and under good conditions. The BIS target level ranged from moderate to deep sedation, at which a stable BIS score between 60 and 80 was obtained [14]. The data including the ASA classification of the patient, dose of propofol, the propofol concentration setting on $\mathrm{TCl}$, any adverse effects during the procedure, and procedure time were prospectively entered into a database.

\section{Statistical analysis}

Continuous data are expressed as mean \pm standard deviation (SD). The Wilcoxon rank sum test was used to assess the significance of differences between two independent groups. $P<0.05$ was considered statistically significant.

\section{Results}

$\nabla$

A total of 292 early esophageal (21 lesions in 20 patients) and gastric (271 lesions in 230 patients) tumors in 250 patients were treated by ESD with propofol sedation using the BIS/TCI system. The mean age was $72 \pm 9$ years (range 39-92 years). The male/female ratio was 200:50. The mean sizes of the resected specimen and the lesion were $37 \pm 13 \mathrm{~mm}$ and $13 \pm 10 \mathrm{~mm}$, respectively. All patients were administered propofol sedation using the BIS/TCI system during the procedure. The mean procedure time was $89 \pm 59 \mathrm{~min}$, and the mean dose of propofol was $4.19 \pm 1.32 \mathrm{mg} / \mathrm{kg} / \mathrm{h}$. The medians of the lower and upper bounds of the blood concentration of propofol were $1.2 \mu \mathrm{g} / \mathrm{mL}$ (range $0.6-1.8 \mu \mathrm{g} / \mathrm{mL}$ ) and $1.4 \mu \mathrm{g} / \mathrm{mL}$ (range $1.0-3.8 \mu \mathrm{g} / \mathrm{mL}$ ), respectively. In $80.4 \%$ of patients, it was possible to maintain stable sedation throughout the endoscopic procedure with a blood concentration of propofol of less than $1.6 \mu \mathrm{g} / \mathrm{mL}$ using TCI ( $\bullet$ Fig. 1). Twenty-three of the 250 patients had to be additionally administered pentazocine during the procedure, because there was body movement of the patient despite the increased setting of the target blood concentration of propofol (Ce). These cases had a tendency to be time-consuming and tended to be cases of esophageal cancer. The mean dose of pentazocine was $16.4 \mathrm{mg}$ per patient ( $\bullet$ Table 1 ). Amongst the esophageal cancer cases, there was a significantly higher frequency of relatively young patients than amongst the gastric cancer cases, with more fre- 


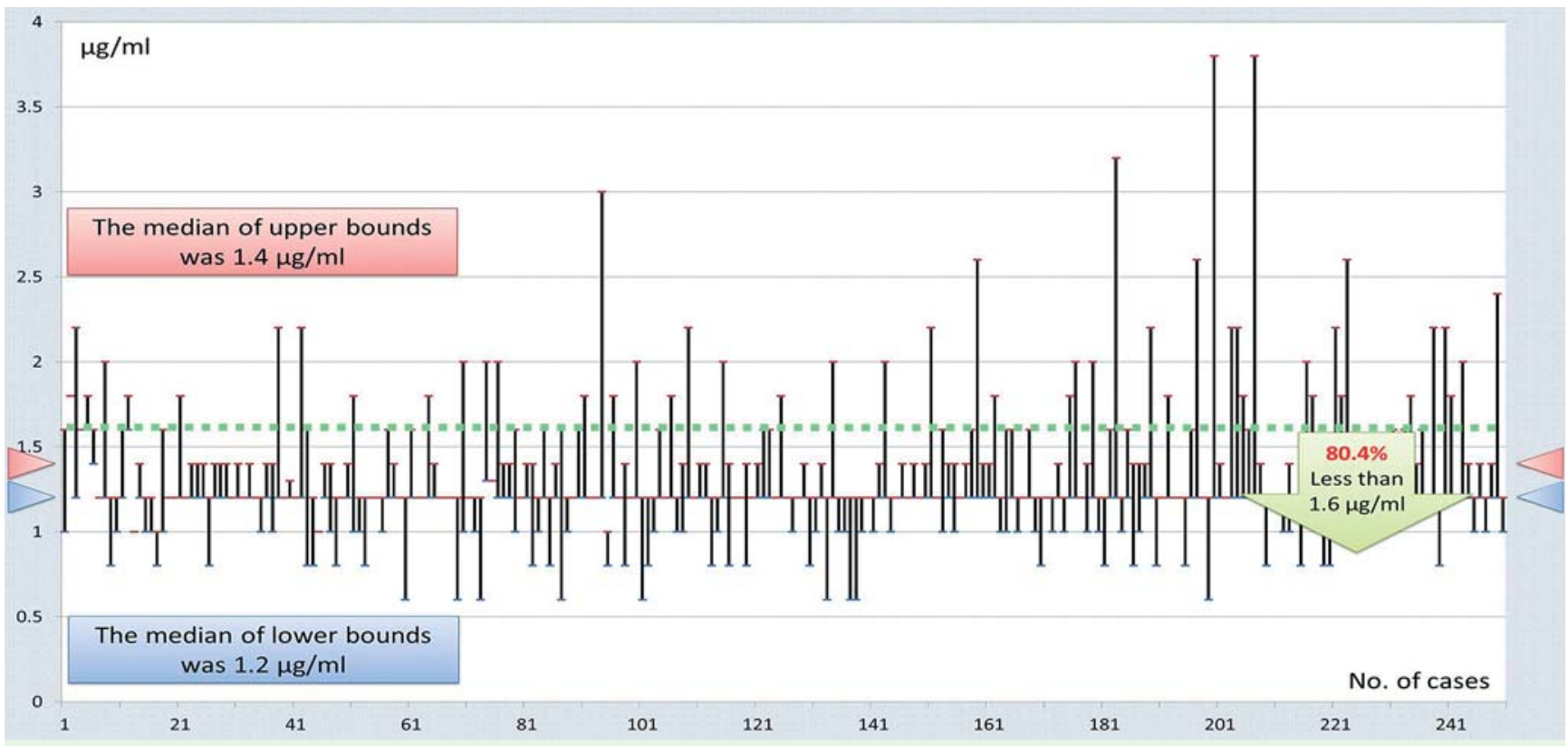

Fig. 1 Blood concentration of propofol in the target-controlled infusion (TCI) system in all patients. In $80.4 \%$ of patients, it was possible to maintain stable sedation with a blood concentration of propofol of less than $1.6 \mu \mathrm{g} / \mathrm{mL}$ using TCl throughout the endoscopic submucosal dissection procedure. The default setting of ideal blood concentration for propofol was set at $1.2 \mu \mathrm{g} / \mathrm{mL}$ because the medians of the lower and upper bounds of the blood concentration of propofol were $1.2 \mu \mathrm{g} / \mathrm{mL}$ (range $0.6-1.8 \mu \mathrm{g} / \mathrm{mL}$ ) and $1.4 \mu \mathrm{g} / \mathrm{mL}$ (range $1.0-3.8 \mu \mathrm{g} / \mathrm{mL}$ ), respectively.

\begin{tabular}{|c|c|}
\hline \multicolumn{2}{|l|}{ Characteristic } \\
\hline No. of patients & 250 \\
\hline Age, mean $\pm S D$ (range), years & $72 \pm 9(39-92)$ \\
\hline Sex, male, n (\%) & $200(80)$ \\
\hline $\mathrm{BW}$, mean $\pm \mathrm{SD}$ (range), $\mathrm{kg}$ & $59 \pm 10(30-81)$ \\
\hline $\mathrm{BMI}$, mean $\pm \mathrm{SD}$ (range) & $23 \pm 3(13-31)$ \\
\hline \multicolumn{2}{|l|}{ ASA class, $n(\%)$} \\
\hline 1 & $67(27)$ \\
\hline 2 & $135(54)$ \\
\hline 3 & $48(19)$ \\
\hline \multicolumn{2}{|l|}{ ESD, $n(\%)$} \\
\hline Esophagus & $20(8)$ \\
\hline Stomach & $230(92)$ \\
\hline \multicolumn{2}{|l|}{ Sedation } \\
\hline Total dose of propofol, mean \pm SD (range), $\mathrm{mg}$ & $345 \pm 256(69-1823)$ \\
\hline Total dose of propofol, mean \pm SD (range), $\mathrm{mg} / \mathrm{kg} / \mathrm{h}$ & $4.2 \pm 1.3(1.6-11.5)$ \\
\hline \multicolumn{2}{|l|}{ Analgesic agent } \\
\hline Total amount of pentazocine, mean \pm SD (range), $\mathrm{mg}$ & $16.4 \pm 4.6(15-45)$ \\
\hline Cases of additional administration of pentazocine, $\mathrm{n}(\%)$ & $23(9)$ \\
\hline \multicolumn{2}{|l|}{ BIS score and TCI } \\
\hline Minimum BIS score, mean \pm SD (range) & $56 \pm 11(27-80)$ \\
\hline Upper bound of blood concentration of propofol, median (range), $\mu \mathrm{g} / \mathrm{mL}$ & $1.4(1.0-3.8)$ \\
\hline Lower bound of blood concentration of propofol, median (range), $\mu \mathrm{g} / \mathrm{mL}$ & $1.2(0.6-1.8)$ \\
\hline
\end{tabular}

Table 1 Clinical and procedural characteristics of the patients.

BW, body weight; BMI, body mass index; ASA, American Society of Anesthesiologists' classification; ESD, endoscopic submucosal dissection; $\mathrm{BIS}$, bispectral index monitor; $\mathrm{TCl}$, target-controlled infusion.

quent additional pentazocine administration, higher propofol doses and higher values of the upper bound of blood concentration of propofol in the TCI system ( Table 2). Although hypotension occurred in 27 patients (10.8\%), oxygen desaturation occurred in only nine patients $(3.6 \%)$, and severe desaturation in only two patients $(0.8 \%)$ ( Table 3$)$.

All cases of oxygen desaturation were resolved through conservative therapy or by increasing the concentration of supplied oxygen. There were no severe adverse events involving propofol sedation during the ESD procedures.

\section{Discussion}

By administering propofol, it was possible to maintain moderate to deep sedation during complex endoscopic procedures. However, there is a need for a suitable and safe method of propofol administration by non-anesthesiologists. Propofol administration via a target-controlled infusion system with a bispectral index monitor (BIS/TCI system) is expected to prevent complications of sedation during complex and long endoscopic procedures such as gastric and esophageal ESD. In the results of this study, using our settings for the BIS/TCI system, it was possible 
Table 2 Results of the procedure and sedation between the groups.

\begin{tabular}{|c|c|c|c|}
\hline & Esophagus & Stomach & $P$ value \\
\hline No. of patients (lesions) & $20(21)$ & $230(271)$ & \\
\hline Age, mean $\pm S D$, years & $67 \pm 11$ & $72 \pm 9$ & $<0.05$ \\
\hline Sex, male, n (\%) & $19(95)$ & $181(79)$ & \\
\hline $\mathrm{BW}$, mean $\pm \mathrm{SD}, \mathrm{kg}$ & $58 \pm 10$ & $59 \pm 11$ & 0.53 \\
\hline $\mathrm{BMI}$, mean $\pm S D$ & $21 \pm 3$ & $23 \pm 3$ & $<0.05$ \\
\hline \multicolumn{4}{|l|}{ ASA class, $n(\%)$} \\
\hline 1 & $6(30)$ & $61(27)$ & \\
\hline 2 & $10(50)$ & $125(54)$ & \\
\hline 3 & $4(20)$ & $44(19)$ & \\
\hline \multicolumn{4}{|l|}{ Sedation } \\
\hline Total amount of propofol, mean \pm SD, mg & $574 \pm 459$ & $326 \pm 221$ & $<0.01$ \\
\hline Total dose of propofol, mean \pm SD, $\mathrm{mg} / \mathrm{kg} / \mathrm{h}$ & $4.8 \pm 1.1$ & $4.1 \pm 1.3$ & $<0.01$ \\
\hline \multicolumn{4}{|l|}{ Analgesic agent } \\
\hline Total dose of pentazocine, mean $\pm S D, \mathrm{mg}$ & $19 \pm 8$ & $16 \pm 4$ & 0.12 \\
\hline Cases of additional administration, $\mathrm{n}(\%)$ & $4(20)$ & $19(8)$ & $<0.05$ \\
\hline \multicolumn{4}{|l|}{ BIS score and TCI } \\
\hline Minimum BIS score, mean \pm SD & $58 \pm 12$ & $56 \pm 11$ & 0.37 \\
\hline Upper bound of blood concentration of propofol, median (range), $\mu \mathrm{g} / \mathrm{mL}$ & $1.8(1.0-3.8)$ & $1.3(1.0-3.8)$ & $<0.001$ \\
\hline Lower bound of blood concentration of propofol, median (range), $\mu \mathrm{g} / \mathrm{mL}$ & $1.2(0.8-1.6)$ & $1.2(0.6-1.8)$ & 0.21 \\
\hline Time of procedure, mean \pm SD, min & $111 \pm 91$ & $79 \pm 54$ & 0.10 \\
\hline
\end{tabular}

BW, body weight; BMI, body mass index; ASA, American Society of Anesthesiologists' classification; ESD, endoscopic submucosal dissection; BIS, bispectral index monitor; TCI, target-controlled infusion.

Table 3 Adverse events during the ESD procedure using the BIS/TCI system.

\begin{tabular}{|lc|}
\hline Adverse event & $\mathbf{n}(\%)$ \\
\hline Hypotension $($ syst. $\mathrm{BP}<90 \mathrm{mmHg}), \mathrm{n}(\%)$ & $27(10.8)$ \\
\hline Hypoxemia $\left(\mathrm{SpO}_{2}<90 \%\right), \mathrm{n}(\%)$ & $9(3.6)$ \\
\hline Severe hypoxemia $\left(\mathrm{SpO}_{2}<85 \%\right), \mathrm{n}(\%)$ & $2(0.8)$ \\
\hline
\end{tabular}

for a non-anesthesiologist to maintain stable sedation during a lengthy endoscopic procedure through propofol sedation. In addition, after setting the target blood concentration of propofol (Ce), it was possible to carry out safe endoscopic therapy while the BIS/TCI system monitored the BIS score, vital signs and movement of the patient. The ideal setting for the initial $\mathrm{Ce}$ was $1.2 \mu \mathrm{g} / \mathrm{mL}$, because the median of the lower bound of Ce was $1.2 \mu \mathrm{g} / \mathrm{mL}$ (range $0.6-1.8 \mu \mathrm{g} / \mathrm{mL}$ ) and in $80.4 \%$ of all patients, it was possible to maintain stable sedation with a Ce of less than $1.6 \mu \mathrm{g} / \mathrm{mL}$ using TCI.

Propofol administered by TCI was first described in 1989 [21]. TCI automatically provided computer-controlled pump infusions of propofol depending on the patient's weight. Several studies have reported that TCI has benefits in bidirectional endoscopy (esophagogastroduodenoscopy followed by colonoscopy) [16], endoscopic retrograde cholangiopancreatography (ERCP) [17, 28,29 ], colonoscopy [30], dental surgery [22], sleep nasopharyngoscope examination [31], direct laryngoscopy and bronchoscopy [32].

We set the initial target blood concentration of propofol at $1.2 \mu \mathrm{g} /$ $\mathrm{mL}$ in the TCI system. There have been some studies in Western countries that reported the default concentration of TCI as $2.0-$ $4.0 \mu \mathrm{g} / \mathrm{mL}$; however, a high rate of decline of $\mathrm{SpO}_{2}$ was observed $[15,16]$. In addition, in dental anesthesia in Japan, there was a report that moderate sedation was obtained in Japanese patients with a blood concentration of propofol of $1.2 \mu \mathrm{g} / \mathrm{mL}$ [22]. There may be ethnic differences in the metabolism of propofol; it was possible to obtain sufficient sedation even after setting the target concentration of propofol at $1.2 \mu \mathrm{g} / \mathrm{mL}$ in the TCI system. Because our initial setting of Ce using the TCI system was lower than that in other reports, it required about $5 \mathrm{~min}$ at the start of treatment for BIS values to become 80 or less. However, it is believed that slow administration of propofol is most important to achieve safe sedation because, in general, desaturation may occur if propofol is administered too rapidly.

The efficacy and utility of a BIS monitor for propofol sedation during endoscopic procedures have not been proven, because use of a BIS monitor is not able to reduce the dose of propofol. However, with reference to the value of BIS, it is easy to adjust the settings of the TCI system. Also, by using the BIS monitor, the operator will be able to perform the entire procedure with confidence by monitoring the level of sedation objectively. Upon comparison of patients with gastric or esophageal lesions, a higher value of blood concentration of propofol should be set in the TCI system in patients with esophageal lesions than in those with gastric lesions. However, since the number of cases was small, it will be necessary to accumulate more cases in the future.

In conclusion, using our settings in the BIS/TCI system, it is possible for a non-anesthesiologist to maintain stable sedation with propofol during a lengthy endoscopic procedure.

\section{Competing interests: None}

\section{References}

1 Sethi S, Wadhwa V, Thaker A et al. Propofol versus traditional sedative agents for advanced endoscopic procedures: A meta-analysis. Dig Endosc 2013 [Epub ahead of print]

2 Wang $D$, Chen $C$, Chen J et al. The use of propofol as a sedative agent in gastrointestinal endoscopy: a meta-analysis. PLoS One 2013; 8: e53311

3 Cohen LB, Wecsler JS, Gaetano JN et al. Endoscopic sedation in the United States: results from a nationwide survey. Am J Gastroenterol 2006; 101: $967-974$

4 Triantafillidis JK, Merikas E, Nikolakis D et al. Sedation in gastrointestinal endoscopy: current issues. World J Gastroenterol 2013; 28: 463 481 
5 Weston BR, Chadalawada V, Chalasani $N$ et al. Nurse administered propofol versus midazolam and meperidine for upper endoscopy in cirrhotic patients. Am J Gastroenterol 2003; 98: 2440 - 2447

6 Vargo JJ, Zuccaro GJr et al. Gastroenterologist administered propofol versus meperidine and midazolam for advanced upper endoscopy: A prospective, randomized trial. Gastroenterology 2002; 123: 8-16

7 Heuss LT, Schnieper P, Drewe J et al. Risk stratification and safe administration of propofol by registered nurses supervised by the gastroenterologist: A prospective observational study of more than 2000 cases. Gastrointest Endosc 2003; 57: 664-671

8 Dumonceau JM, Riphaus A, Aparicio JR et al. European Society of Gastrointestinal Endoscopy, European Society of Gastroenterology and Endoscopy Nurses and Associates, and the European Society of Anaesthesiology Guideline: Non-anesthesiologist administration of propofol for GI endoscopy. Endoscopy 2010; 42: 960 -974

9 Vargo JJ, Cohen LB, Rex DK et al. Position statement: Nonanesthesiologist administration of propofol for GI endoscopy. Gastroenterology 2009; 137: 2161 - 2167

10 Friedrich K, Stremmel W, Sieg A. Endoscopist-administered propofol sedation is safe - a prospective evaluation of 10,000 patients in an outpatient practice. J Gastrointest Liver Dis 2012; 21: 259-263

11 Yusoff IF, Raymond G, Sahai AV. Endoscopist administered propofol for upper-GI EUS is safe and effective: a prospective study in 500 patients. Gastrointest Endosc 2004; 60: 356-360

12 Tohda G, Higashi S, Sakumoto H et al. Efficacy and safety of nurse-administered propofol sedation during emergency upper endoscopy for gastrointestinal bleeding: a prospective study. Endoscopy 2006; 38: 684-689

13 Tohda G, Higashi S, Wakahara S et al. Propofol sedation during endoscopic procedures: safe and effective administration by registered nurses supervised by endoscopists. Endoscopy 2006; 38: 360 - 367

14 Imagawa A, Fujiki S, Kawahara $Y$ et al. Satisfaction with bispectral index monitoring of propofol-mediated sedation during endoscopic submucosal dissection: a prospective, randomized study. Endoscopy 2008; 40: 905-909

15 Chiang $\mathrm{MH}, \mathrm{Wu} \mathrm{SC}$, You $\mathrm{CH}$ et al. Target-controlled infusion vs. manually controlled infusion of propofol with alfentanil for bidirectional endoscopy: a randomized controlled trial. Endoscopy 2013; 45: 907 914

16 Mazanikov M, Udd M, Kylänpää $L$ et al. A randomized comparison of target-controlled propofol infusion and patient-controlled sedation during ERCP. Endoscopy 2013; 45: 915-919

17 Friedrich RM, Welte $M$, Welte $C$ et al. Capnographic monitoring of propofol-based sedation during colonoscopy. Endoscopy 2013 [Epub ahead of print]

18 Beitz A, Riphaus A, Meining A et al. Capnographic monitoring reduces the incidence of arterial oxygen desaturation and hypoxemia during propofol sedation for colonoscopy: a randomized, controlled study (ColoCap Study). Am J Gastroenterol 2012; 107: 1205-1212

19 Gotoda T, Kusano C, Nonaka $M$ et al. Non-anesthesiologist administrated propofol (NAAP) during endoscopic submucosal dissection for elderly patients with early gastric cancer. Gastric Cancer 2014: DOI: DOI 10.1007/s10120-013-0336-9

20 Paspatis GA, Chainaki I, Manolaraki MM et al. Efficacy of bispectral index monitoring as an adjunct to propofol deep sedation for ERCP: a randomized controlled trial. Endoscopy 2009; 41: 1046 - 1051

21 Tackley RM, Lewis GT, Prys-Roberts C et al. Computer controlled infusion of propofol. Br J Anaesth 1989; 62: 46-53

22 Sakaguchi M, Higuchi $H$, Maeda $S$ et al. Dental sedation for patients with intellectual disability: a prospective study of manual control versus Bispectral Index-guided target-controlled infusion of propofol. J Clin Anesth 2011; 23: 636-642

23 Imagawa A, Okada H, Kawahara Y et al. Endoscopic submucosal dissection for early gastric cancer: results and degrees of technical difficulty as well as success. Endoscopy 2006; 38: 987-990

24 Yahagi N, Uraoka T, Ida Yet al. Endoscopic submucosal dissection using the Flex and the Dual knives. Tech Gastrointest Endosc 2011; 13: $74-$ 78

25 Shimizu Y, Takahashi M, Yoshida T et al. Endoscopic resection (endoscopic mucosal resection/endoscopic submucosal dissection) for superficial esophageal squamous cell carcinoma: current status of various techniques. Dig Endosc 2013; 25: 13 -19

26 Kawahara Y, Hori K, Takenaka $R$ et al. Endoscopic submucosal dissection of esophageal cancer using the Mucosectom2 device: a feasibility study. Endoscopy 2013; 45: 869-875

27 Okudera H, Wakasugi M. Immediate Cardiac Life Support (ICLS) course developed by Japanese Association for Acute Medicine. Nihon Rinsho 2011; 69: 684-690, Article in Japanese

28 Fanti L, Agostoni M, Casati A et al. Target-controlled propofol infusion during monitored anesthesia in patients undergoing ERCP. Gastrointest Endosc 2004; 60: 361 - 366

29 Gillham MJ, Hutchinson RC, Carter R et al. Patient-maintained sedation for ERCP with a target-controlled infusion of propofol: a pilot study. Gastrointest Endosc 2001; 54: 14-17

30 Moerman AT, Herregods LL, De Vos MM et al. Manual versus target-controlled infusion remifentanil administration in spontaneously breathing patients. Anesth Analg 2009; 108: 828-834

31 De Vito A, Agnoletti V, Berrettini S et al. Drug-induced sleep endoscopy: conventional versus target controlled infusion techniques - a randomized controlled study. Eur Arch Otorhinolaryngol 2011; 268: 457-462

32 Passot S, Servin F, Allary R et al. Target-controlled versus manually-controlled infusion of propofol for direct laryngoscopy and bronchoscopy. Anesth Analg 2002; 94: 1212-1216 